\title{
SphK1 modulates cell migration and EMT-related marker expression by regulating the expression of p-FAK in colorectal cancer cells
}

\author{
CHUN-YAN XU, SHI-QUAN LIU, MENG-BIN QIN, CHUN-FENG ZHUGE, \\ LIN QIN, NAN QIN, MING-YU LAI and JIE-AN HUANG \\ Department of Gastroenterology, The First Affiliated Hospital of \\ Guangxi Medical University, Nanning, Guangxi 530021, P.R. China
}

Received January 19, 2016; Accepted March 10, 2017

DOI: $10.3892 / \mathrm{ijmm} .2017 .2921$

\begin{abstract}
Sphingosine kinase 1 (SphK1) plays an important role in colorectal carcinoma metastasis. However, whether SphK1 modulates epithelial-mesenchymal transition (EMT)related marker expression and the underlying mechanisms remain unclear. In this study, in order to clarify this issue, we used various colorectal cancer (CRC) cell lines, Caco2, HT29, RKO and HCT116. Each of the cell lines was divided into 3 groups as follows: the control group, SKI-II (SphK1 inhibitor) group and PF-562271 [focal adhesion kinase (FAK) inhibitor] group. The migratory ability of the cells was examined by Transwell chamber assay. The mRNA and protein expression levels of SphK1, FAK (p-FAK), Slug, vimentin, N-cadherin and E-cadherin were detected by PCR and western blot analysis, respectively. The results revealed that the suppression of SphK1 reduced the cell migratory ability, and decreased the expression of Slug, vimentin and N-cadherin; however, the expression of E-cadherin was increased. Moreover, the inhibition of SphK1 reduced the expression of p-FAK. The inhibition of FAK (p-FAK) also decreased the cell migratory ability, and decreased the expression of Slug, vimentin and $\mathrm{N}$-cadherin, whereas the expression of E-cadherin was increased. Thus, our data suggest that SphK1 modulates the expression of EMT-related markers and cell migration by regulating the expression of p-FAK in CRC cells. Thus, SphK1 may play a functional role in mediating the EMT process in CRC.
\end{abstract}

Correspondence to: Professor Shi-Quan Liu or Professor Jie-An Huang, Department of Gastroenterology, The First Affiliated Hospital of Guangxi Medical University, 6 Shuangyong Road, Nanning, Guangxi 530021, P.R. China

E-mail: poempower@163.com

E-mail: 1404991727@qq.com

Key words: colorectal cancer, E-cadherin, focal adhesion kinase, sphingosine kinase 1

\section{Introduction}

Colorectal cancer (CRC) is a leading cause of cancer-related mortality (1). Metastasis is the most related cause of the majority of human cancer-related deaths (2). Metastasis is a complex process and many scientists have strived to understand the mechanisms behind this phenomenon over the years (3); however, the mechanisms responsible for the occurrence of metastasis remain to be fully elucidated. The treatment of colon cancer involves a comprehensive therapeutic approach (4). Thus, the more in depth understanding of the mechanisms responsible for CRC metastasis may provide valuable direction and an experimental basis for its treatment in future.

Epithelial-mesenchymal transition (EMT) had been highlighted as a process through which epithelial cells lose their characteristics and gain mesenchymal properties to be motile, playing a critical role in the metastasis of cancer cells $(5,6)$. Among the EMT-related transcription factors, the Snail family of zing finger transcription factors is prominent, particularly Slug (Snail2) $(7,8)$. Stimulating Slug expression has been shown to suppress E-cadherin and to concomitantly upregulate $\mathrm{N}$-cadherin expression $(9,10)$. Moreover, Slug induces vimentin expression (11). Therefore, Slug regulates E-cadherin and $\mathrm{N}$-cadherin, and vimentin expression.

Sphingosine kinase 1 (SphK1) is an oncogenic enzyme which promotes the transformation, proliferation and angiogenesis of a number of human tumors $(12,13)$. Recent studies have indicated that SphK1 is involved in regulating the NF- $\mathrm{kB}$ pathways $(14,15)$, AKT (16) and focal adhesion kinase (FAK) (17) in cancer. We wished to determine whether SphK1 potentially promotes the EMT process in CRC cells, as it has been previously shown to promote EMT in lung cancer cells (18).

To date, some researchers have discovered that FAK plays an important role in EMT and influences the expression of EMT-related makers (19-21). Thus, we hypothesized that SphK1 may affect metastasis, and the expression of Slug, E-cadherin, $\mathrm{N}$-cadherin and vimentin via the FAK pathway in CRC cells. In order to confirm our hypothesis, in this study, we used various CRC cells, and we found indeed, that SphK1 modulates the expression of EMT-related markers by regulating the expression of p-FAK in CRC cells. 


\section{Materials and methods}

Cell lines and cell culture. The human colorectal carcinoma cell lines, Caco2 (Boster, Wuhan, China), HT29, RKO and HCT116 (R\&S Biotechnology Co., Ltd., Shanghai, China) were routinely cultured in DMEM containing $100 \mathrm{ml} / \mathrm{l}$ fetal bovine serum (FBS; ExCell Bio, Shanghai, China) and incubated at $37^{\circ} \mathrm{C}$ with $5 \% \mathrm{CO}_{2}$.

Each of the cell lines was divided into 3 groups as follows: the control group (N group), the SKI-II (an inhibitor of SphK1) intervention group (SK group) and PF-562271 (an inhibitor of FAK) intervention group (PF group). The cells in the SK group were cultured for $24 \mathrm{~h}$ and then incubated with SKI-II (Selleck, Houston, TX, USA) at $20 \mu \mathrm{M}$ (22) for $48 \mathrm{~h}$. The cells in the $\mathrm{PF}$ group were also cultured for $24 \mathrm{~h}$ and then incubated with PF-562271 (Selleck) $5 \mu \mathrm{M}$ (23) for $48 \mathrm{~h}$.

Transwell chamber assay. The cells were cultured in serumfree medium to produce suspension, and the cell density was adjusted to $5 \times 10^{5} / \mathrm{ml}$. Subsequently, $200 \mu \mathrm{l}$ cell suspension were added to the upper chamber of the Transwell (Corning, Inc., Corning, NY, USA), while $600 \mu \mathrm{l}$ medium including $10 \%$ FBS were added to the bottom chamber, followed by incubation for a period of $24 \mathrm{~h}$ at $37^{\circ} \mathrm{C}$. The assay was terminated as a result of the removal of the medium from the upper well and the filter was fixed with methanol for $10 \mathrm{~min}$. The cells in the upper chamber were wiped off and the cells migrating to the lower side of the upper chamber were stained with $0.1 \%$ crystal violet (Beyotime, Shanghai, China) for $30 \mathrm{~min}$. Random fields were scanned (6 fields/filter) under a fluorescent inverted phase contrast microscope (magnification, x200; TS100-F; Nikon, Tokyo, Japan) for the presence of the cells at the lower membrane side only.

RNA isolation, $c D N A$ synthesis and quantitative PCR (qPCR). RNA isolation was performed using a RNA extraction kit (Tiangen, Beijing, China) according to the manufacturer's instruction. cDNA synthesis was performed using a reverse transcription kit (Takara, Dalian, Japan). Fluorescence-based qPCR was performed using $2 \mu \mathrm{l}$ of cDNA and SYBR-Green (Takara) in a total volume of $20 \mu \mathrm{l}$ and using the ABI 7500 Real-time PCR system (Applied Biosystems, Rockford, IL, USA). The cycling parameters were: $95^{\circ} \mathrm{C}$ for $30 \mathrm{sec}$ followed by 40 cycles at $95^{\circ} \mathrm{C}$ for $5 \mathrm{sec}$ and $60^{\circ} \mathrm{C}$ for $34 \mathrm{sec}$, and a dissociation program that included $95^{\circ} \mathrm{C}$ for $15 \mathrm{sec}, 60^{\circ} \mathrm{C}$ for $1 \mathrm{~min}$, and $95^{\circ} \mathrm{C}$ for $15 \mathrm{sec}$ ramping up at $0.2^{\circ} \mathrm{C} / \mathrm{sec}$. Gene expression levels were determined with the $2^{-\Delta \Delta \mathrm{Cq}}$ method using glyceraldehyde 3-phosphate dehydrogenase (GAPDH) as a reference and the non-stimulated condition was set to 1 . The forward and reverse primers (Takara) of the genes are listed in Table I.

Western blot analysis. The cells were collected using cell scrapers and lysed with RIPA lysis buffer supplemented with $1 \%$ protease and $1 \%$ phosphatase inhibitor for $30 \mathrm{~min}$ following 2 washes with cold phosphate-buffered saline (PBS). The cells were subjected to centrifugation at $12,000 \mathrm{x} \mathrm{g} / \mathrm{min}$ for $15 \mathrm{~min}$ at $4^{\circ} \mathrm{C}$ to remove the cell debris. Protein concentrations were measured by bicinchoninic acid (BCA) assay (Solarbio, Beijing, China) according to the standard protocol.
Table I. The primers used in this study.

\begin{tabular}{ll}
$\begin{array}{l}\text { Gene name } \\
\text { protein name) }\end{array}$ & \multicolumn{1}{c}{\begin{tabular}{c}
\multicolumn{1}{c}{ Sequence primers } \\
$\left(5^{\prime} \rightarrow 3^{\prime}\right)$
\end{tabular}} \\
\hline GAPDH & F: GCACCGTCAAGGCTGAGAAC \\
(GAPDH) & R: TGGTGAAGACGCCAGTGGA \\
SPHK1 & F: GGCTTCATTGCTGATGTGGA \\
(SphK1) & R: AGGAAGGTGCCCAGAGTGAA \\
FAK & F: CAACCACCTGGGCCAGTATTATC \\
(FAK) & R: CCATAGCAGGCCACATGCTTTA \\
SLUG & F: TTTGCAAGATCTGCGGCAAG \\
(Slug) & R: CTGCAAATGCTCTGTTGCAGTG \\
VIM & F: TGACATTGAGATTGCCACCTACAG \\
(vimentin) & R: TCAACCGTCTTAATCAGAAGTGTCC \\
CDH2 & F: AGCACAGTGGCCACCTACAAAG \\
(N-cadherin) & R: CAGCTCCTGGCCCAGTTACA \\
CDH1 & F: GAGTGCCAACTGGACCATTCAGTA \\
(E-cadherin) & R: AGTCACCCACCTCTAAGGCCATC \\
\hline
\end{tabular}

GAPDH, glyceraldehyde 3-phosphate dehydrogenase; SPHK1, sphingosine kinase 1; FAK, focal adhesion kinase.

Equal amounts of protein were separated by sodium dodecyl sulfate-polyacrylamide gel electrophoresis (SDS-PAGE) and then blotted onto 0.45 nitrocellulose membranes. The membranes were subsequently blocked in non-fat milk [dissolved in Tris-buffered saline with 5\% Tween-20 (TBST)] buffer at room temperature for $30 \mathrm{~min}$ to block non-specific binding and incubated with antibodies diluted by western blot antibody diluents overnight at $4^{\circ} \mathrm{C}$, and subsequently incubated with secondary fluorescent antibodies (IRDye ${ }^{\circledR} 680 \mathrm{RD}$ Goat anti-Rabbit 925-68071; C60329-11; dilution, 1:10,000; LI-COR Biosciences, Lincoln, NE, USA) for $1 \mathrm{~h}$ at room temperature following 3 washes with TBST. The membranes were scanned using an Odyssey infrared imaging system (LI-COR Biosciences). Relevant signal intensity was determined using LI-COR imaging software (LI-COR Biosciences). The strips were analyzed using Quantity One software (Bio-Rad, Shanghai, China). Antibodies against E-cadherin (3195S; 1:1,000) and p-FAK (Tyr397; 8556P; 1:1,000) were purchased from Cell Signaling Technology (CST, Beverly, MA, USA). Antibodies against SphK1 (10670-1-AP; 1:500), FAK (12636-1-AP; 1:1,000), Slug (12129-1-AP; 1:500), N-cadherin (66219-1-1g; 1:500), vimentin (10366-1-AP; 1:500) and GAPDH (10494-1-AP; 1:1,000) were purchased from Proteintech Group (PTG, Rosemont, IL, USA).

Statistical analysis. Each experiment was repeated at least 3 times. Data were presented as the means \pm SD. The results of Transwell chamber assay and western blot analysis were analyzed using the t-test. The Mann-Whitney $U$ test was used to analyze the results of PCR. Results were considered statistically significant at $\mathrm{P}<0.05$. 

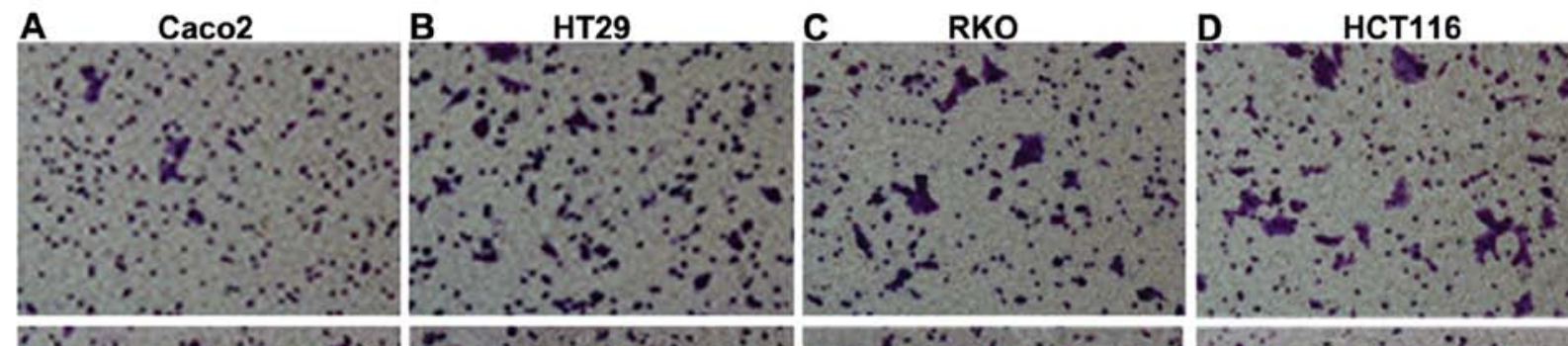

$\mathrm{N}$ group
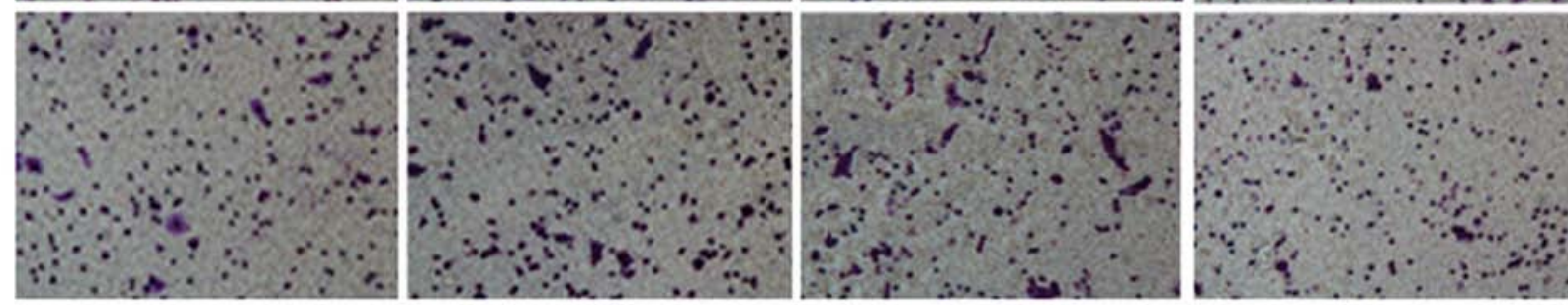

SK group
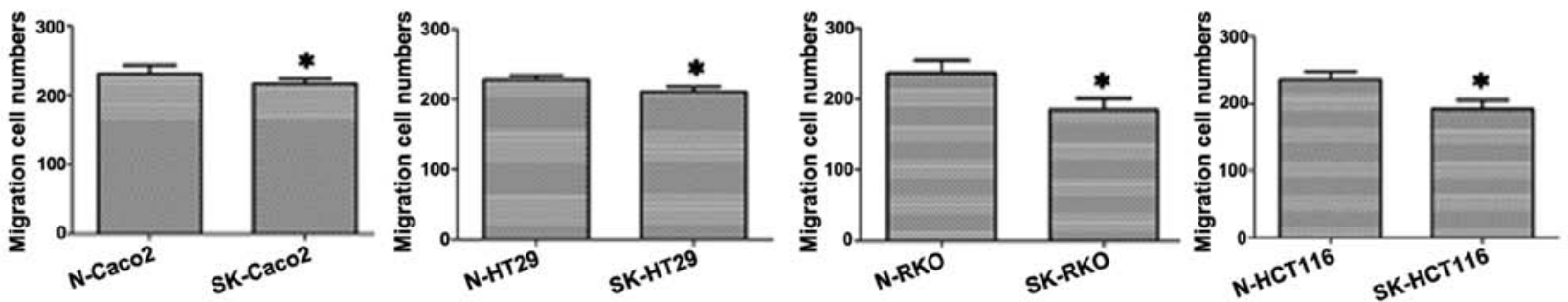

Figure 1. Sphingosine kinase 1 (SphK1) affects colorectal cancer cell migration. The suppression of SphK1 by SKI-II (20 $\mu \mathrm{M})$ for $48 \mathrm{~h}$ (SK group) significantly decreased the number of cells penetrating through the porous membrane. (A) Caco2 cell line. (B) HT29 cell line. (C) RKO cell line. (D) HCT116 cell line. The images are representative of cell penetration (crystal violet staining, magnification, $\mathrm{x} 200$ ) and the data are shown as the means $\pm \mathrm{SD}(\mathrm{P}<0.05 \mathrm{vs}$. $\mathrm{N}$ group).

\section{Results}

Suppression of SphK1 reduces the migratory ability of $C R C$ cells. To examine the effect of SphK1 on the migration of human CRC cells, the cells were exposed to $20 \mu \mathrm{M}$ SKI-II for $48 \mathrm{~h}$, in order to inhibit SphK1 expression. The migrating cells were observed under an inverted microscope. The results revealed that the number of migrating cells in the SK group was significantly lower than that of the cells in the $\mathrm{N}$ group in all 4 CRC cell lines $(\mathrm{P}<0.05$; Fig. 1$)$, indicating that $\mathrm{SphK} 1$ plays an important role in CRC cell migration.

mRNA expression of SphK1, Slug, vimentin, $N$-cadherin and $E$-cadherin detected by fluorescence-based qPCR. In order to investigate the signaling pathways involved in the regulatory effects of SphK1 on the migratory abitlity of CRC cells, some EMT-related markers were examined in the present study. EMT is known to play a critical role in the metastasis of cancer cells $(24,25)$. The mRNA expression of EMT-related makers was detected, including the expression of the transcription factor, Slug (26), the mesenchymal cell markers, vimentin and $\mathrm{N}$-cadherin, and the epithelial cell marker, E-cadherin (27-29). As shown in Fig. 2, the mRNA levels of Slug, vimentin and $\mathrm{N}$-cadherin decreased, whereas that of E-cadherin increased $(\mathrm{P}<0.05)$. This indicated that the suppression of SphK1 suppressed Slug, vimentin and N-cadherin gene expression, while it promoted E-cadherin gene expression.

Protein expression of SphK1, Slug, vimentin, $N$-cadherin and E-cadherin detected by western blot analysis. The results revealed that the expression of Slug, vimentin and N-cadherin decreased, whereas that of E-cadherin increased following the suppression of SphK1 ( $\mathrm{P}<0.05$; Figs. 3 and 4). These results were consistent with those obtained by PCR.

SphK1 is involved in modulating the expression of $p-F A K$. Compared to the $\mathrm{N}$ group, although in the SK group FAK mRNA and total FAK protein expression exhibited no significant difference $(\mathrm{P}>0.05$; Fig. $5 \mathrm{~B}$ and $\mathrm{D})$, $\mathrm{p}-\mathrm{FAK}$ protein expression was markedly decreased $(\mathrm{P}<0.05$; Figs. 3 and $5 \mathrm{E})$. This indicated that SphK1 regulated the expression of p-FAK, suggesting that SphK1 is involved in modulating the FAK pathway.

Inhibition of FAK affects the migratory ability, and the $m R N A$ and protein expression of Slug, vimentin, $N$-cadherin and E-cadherin in CRC cells. To date, some researchers have demonstrated that FAK is involved in regulating the EMT process in cancer cells (30). Moreover, FAK affects the expression of Slug (31). In this study, our results revealed that the numbers of migrating cells in the PF group were lower than those in the $\mathrm{N}$ group in the Caco2, HT29, RKO and HCT116 cells $(\mathrm{P}<0.05$; Fig. 1 and $6 \mathrm{~A})$. In addition, compared with the $\mathrm{N}$ group, the mRNA expression levels of FAK, Slug, vimentin and $\mathrm{N}$-cadherin in the PF group were decreased, whereas the mRNA expression level of E-cadherin was increased $(\mathrm{P}<0.05$; Fig. 6B). Moreover, the protein expression levels of FAK, p-FAK, Slug, vimentin and N-cadherin in the $\mathrm{PF}$ group were lower than the levels in the $\mathrm{N}$ group $(\mathrm{P}<0.05$; Figs. 3 and 6C). Similar with the mRNA expression, the protein 

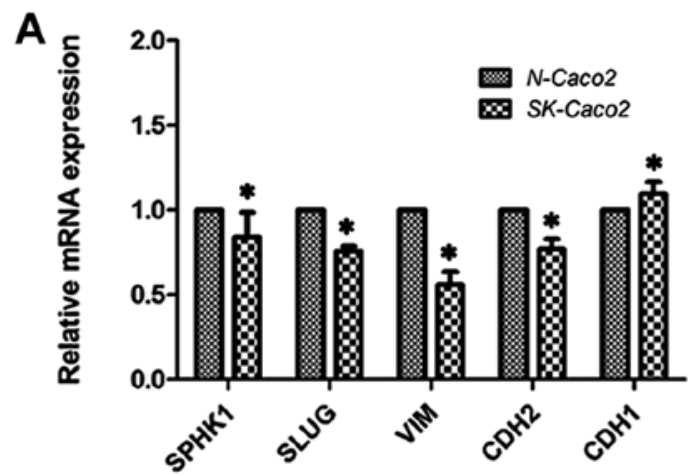

C

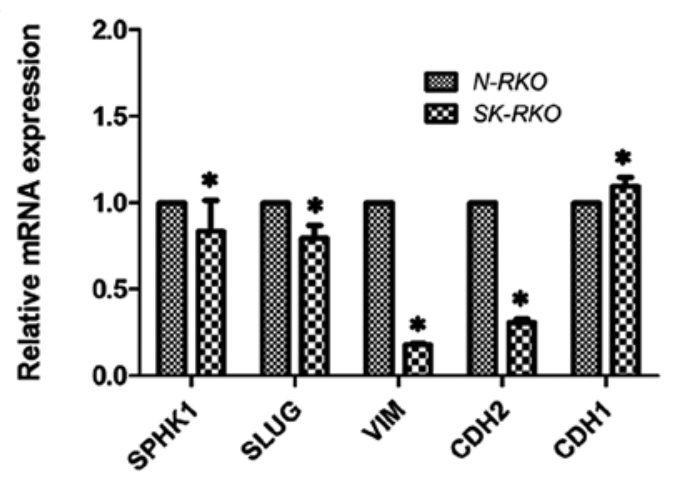

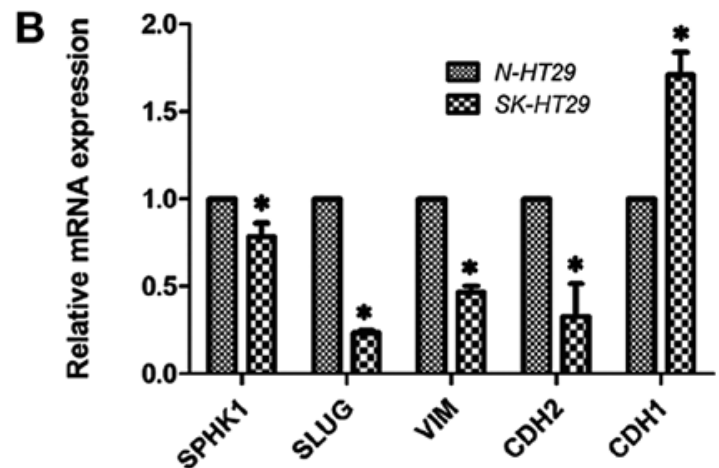

D

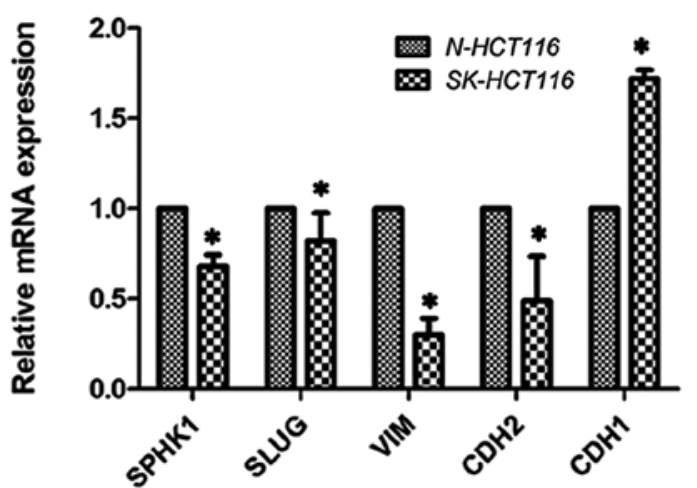

Figure 2. Suppression of sphingosine kinase 1 (SphK1) by SKI-II $20 \mu \mathrm{M}$ for $48 \mathrm{~h}$ (SK group) significantly decreased the mRNA levels of SphK1 (SPHK1), Slug (SLUG), vimentin (VIM), N-cadherin (CDH2), while it increased E-cadherin (CDH1) expression. GAPDH was used as a reference and the unstimulated control (N group) was set to 1. (A) Caco2 cell line. (B) HT29 cell line. (C) RKO cell line. (D) HCT116 cell line. The data were analyzed using the Mann-Whitney U test and are shown as the means $\pm \mathrm{SD}\left({ }^{*} \mathrm{P}<0.05\right.$ vs. $\mathrm{N}$ group).

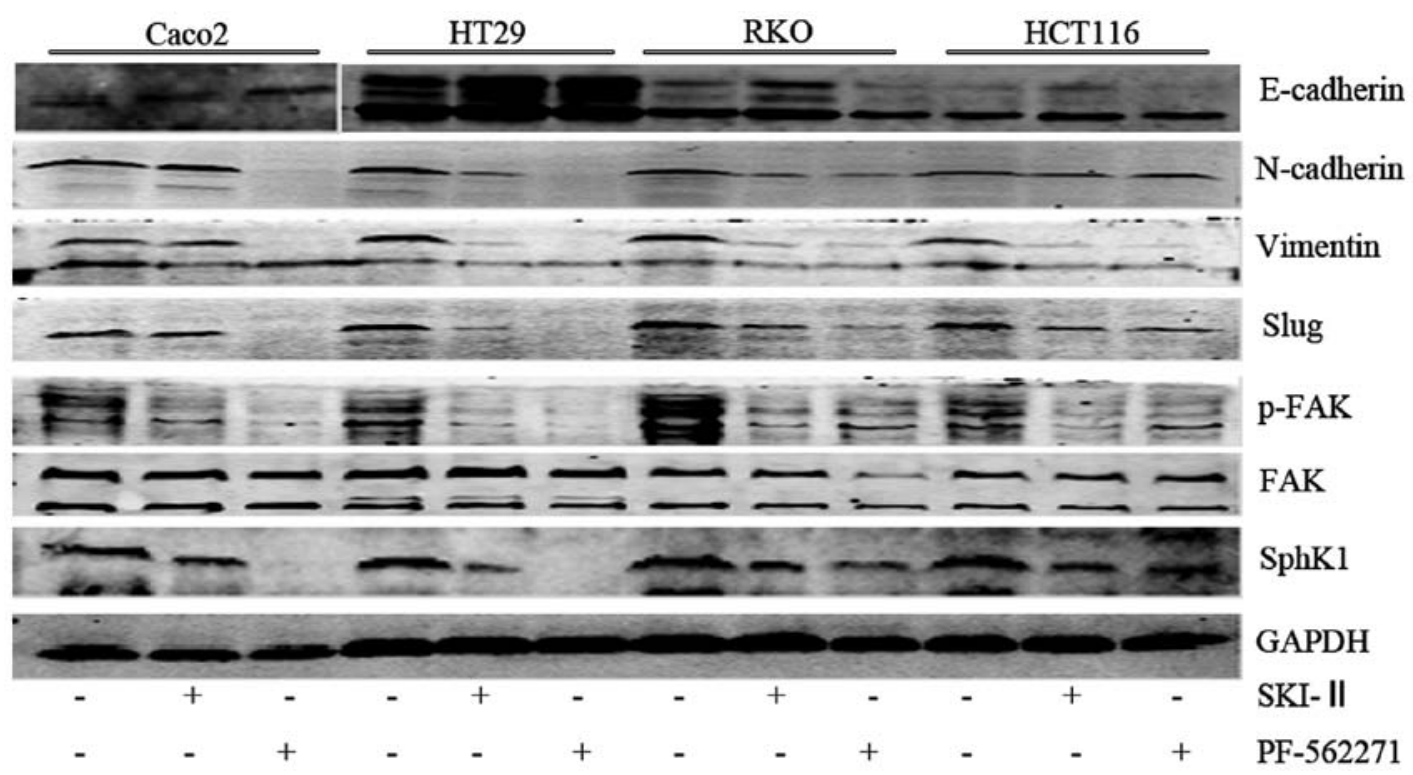

Figure 3. Protein expression of sphingosine kinase 1 (SphK1), FAK, p-FAK, Slug, vimentin, N-cadherin, E-cadherin in Caco2, HT29, RKO, HCT116 cells. '-' indicates culture without SKI-II or PF-562271, while '+' indicates treatment with SKI-II $20 \mu \mathrm{M}$ for 48h or PF-562271 $5 \mu \mathrm{M}$ for $48 \mathrm{~h}$.

expression of E-cadherin in the $\mathrm{PF}$ group was higher than that in the $\mathrm{N}$ group $(\mathrm{P}<0.05$; Figs. 3 and $6 \mathrm{C})$. Thus, the results revealed that FAK may affect the mRNA and protein expression levels of Slug, vimentin, N-cadherin and E-cadherin, as well as the cell migratory ability.
On the whole, according to our data, it can be suggested that SphK1 modulates the expression of Slug, E-cadherin, $\mathrm{N}$-cadherin and vimentin, as well as CRC cell metastasis by regulating the expression of p-FAK in Caco2, HT29, RKO, HCT116 CRC cell lines. 

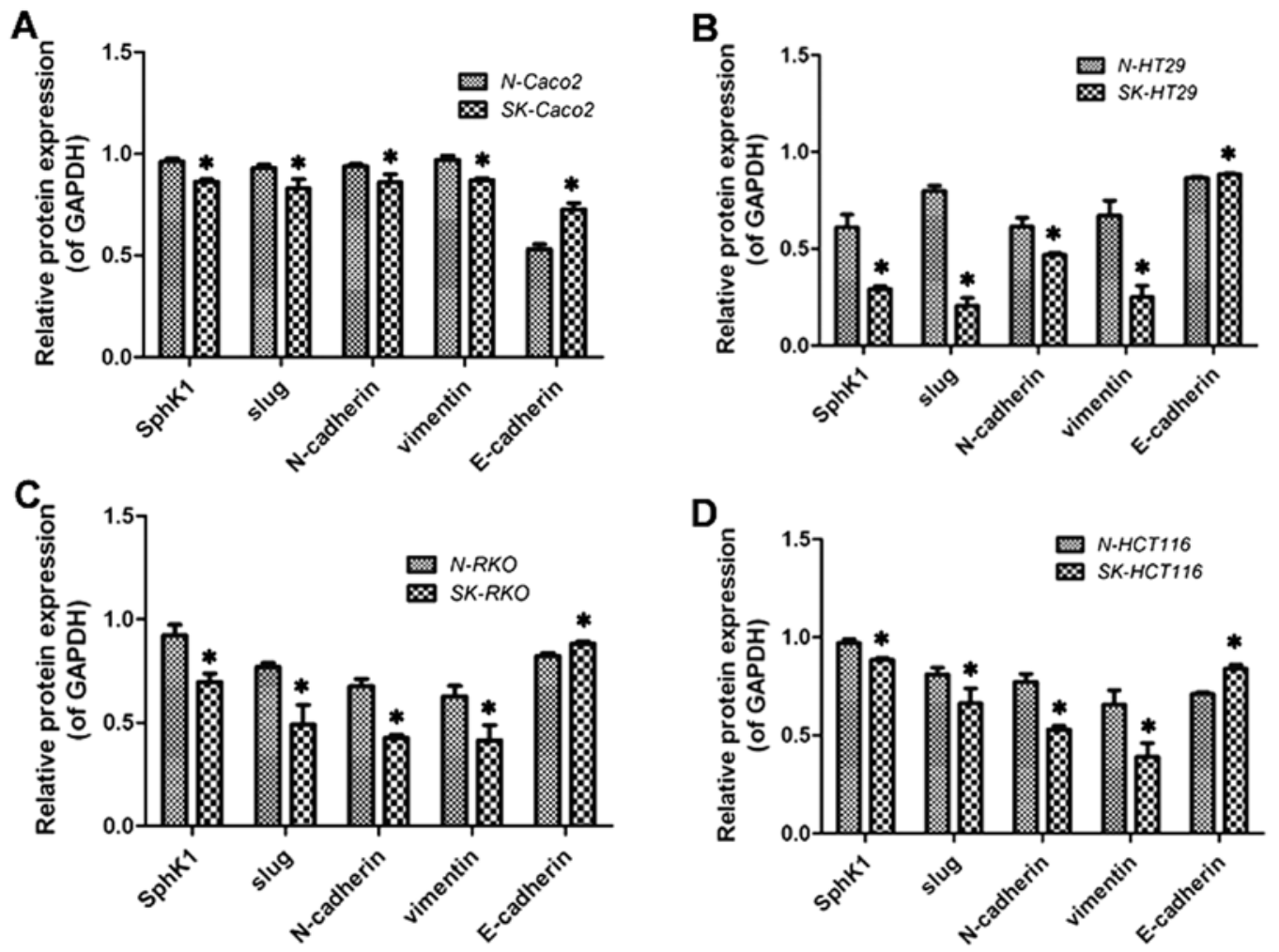

Figure 4. Relative protein expression levels of sphingosine kinase 1 (SphK1), Slug, vimentin, N-cadherin, E-cadherin. GAPDH was used as an internal control. (A) Caco2 cell line. (B) HT29 cell line. (C) RKO cell line. (D) HCT116 cell line. The data were analyzed by the t-test and are shown as the means \pm SD ("P $<0.05$, SK group vs. N group).
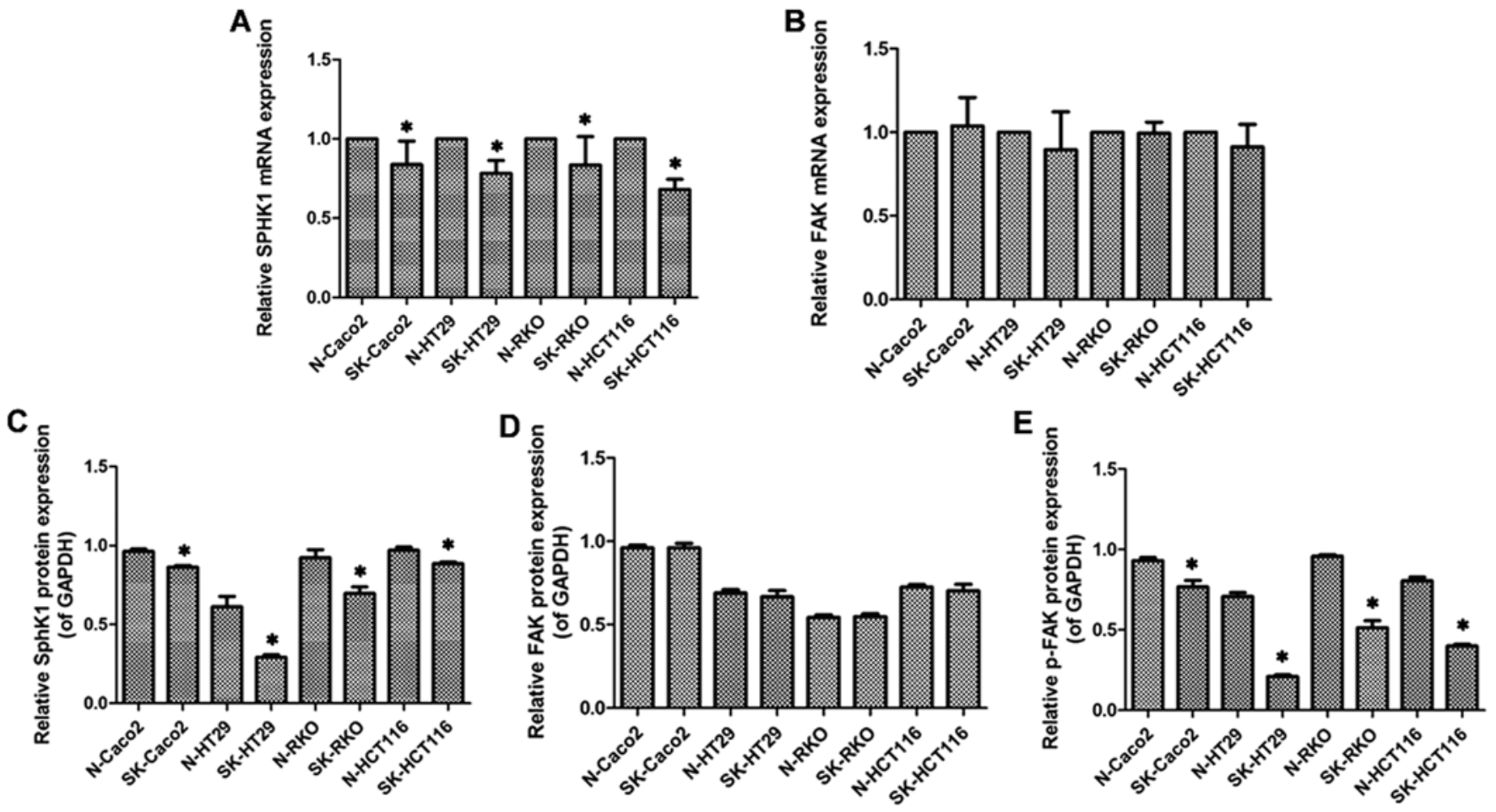

Figure 5. (A and B) The mRNA expression of sphingosine kinase 1 (SphK1) and FAK was detected by fluorescence-based quantitative PCR. GAPDH was used as a reference and the unstimulated control ( $\mathrm{N}$ group) was set to 1 . The data were analyzed using the Mann-Whitney $\mathrm{U}$ test. (C-E) Relative protein expression levels of SphK1, FAK, p-FAK. GAPDH was used as an internal control. The data were analyzed using the t-test. All data are shown as the means \pm SD ("P<0.05 vs. $\mathrm{N}$ group).

\section{Discussion}

SphK1 is a lipid kinase which catalyzes the phosphorylation of sphingosine to S1P. There is evidence to indicate that SphK1 is an oncogenic enzyme, and its activation is closely associated with the transformation, proliferation and survival of tumor 
A

Caco2

HT29

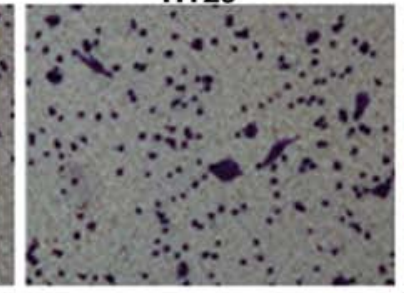

RKO

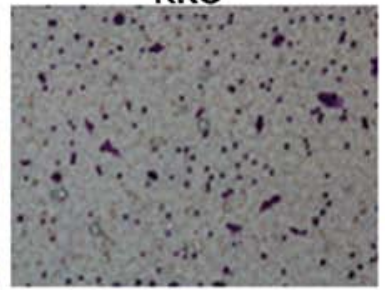

HCT116

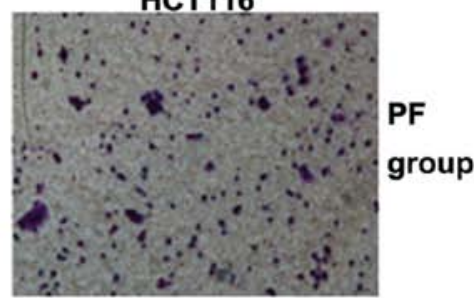

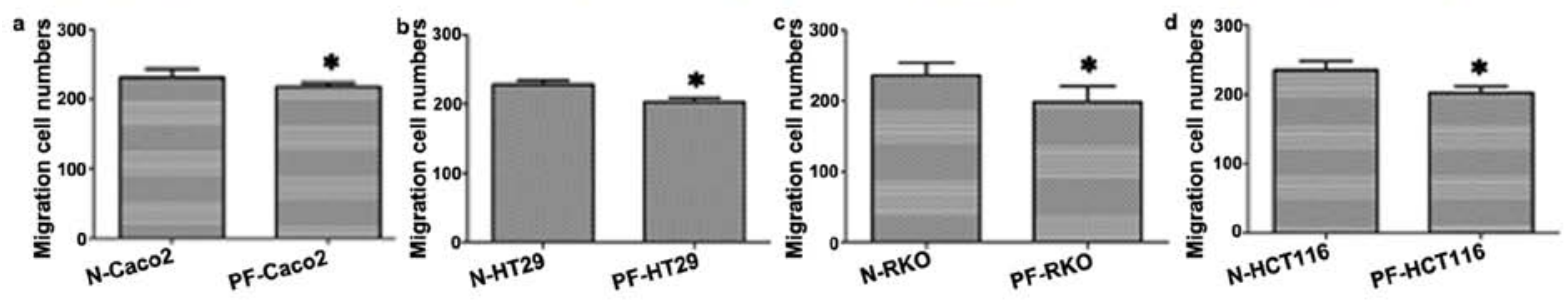

$\mathrm{Ba}$
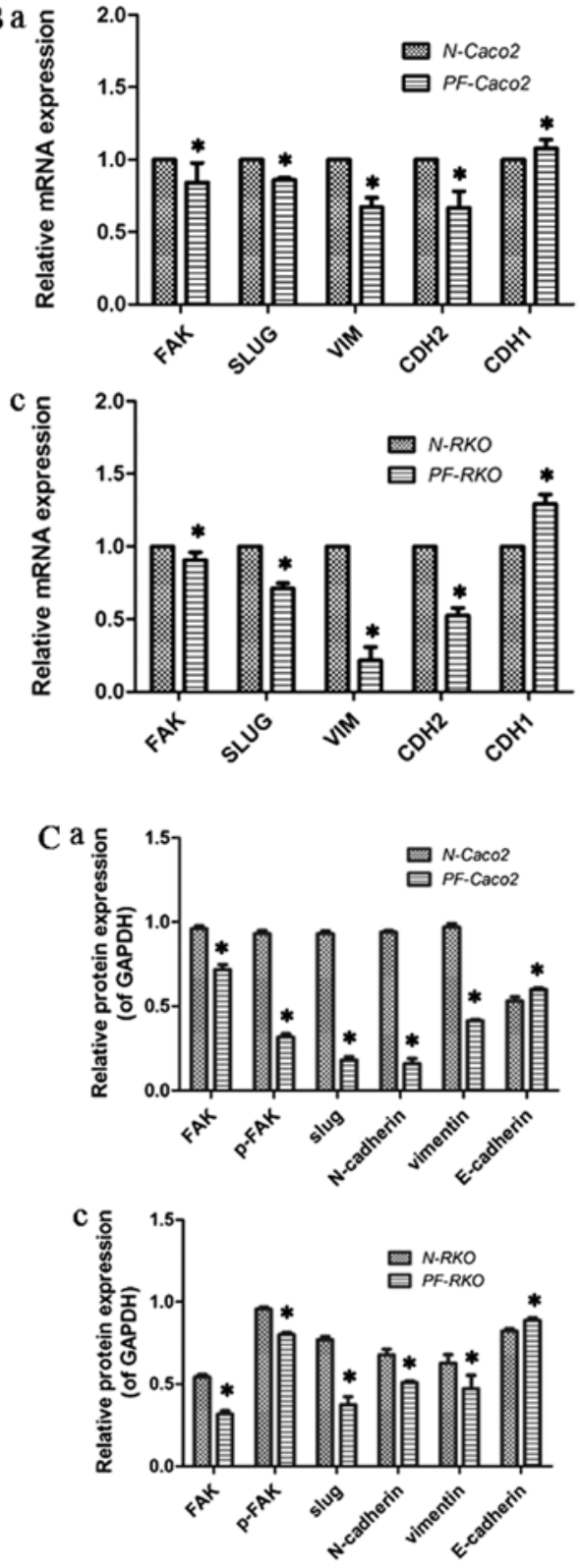

b
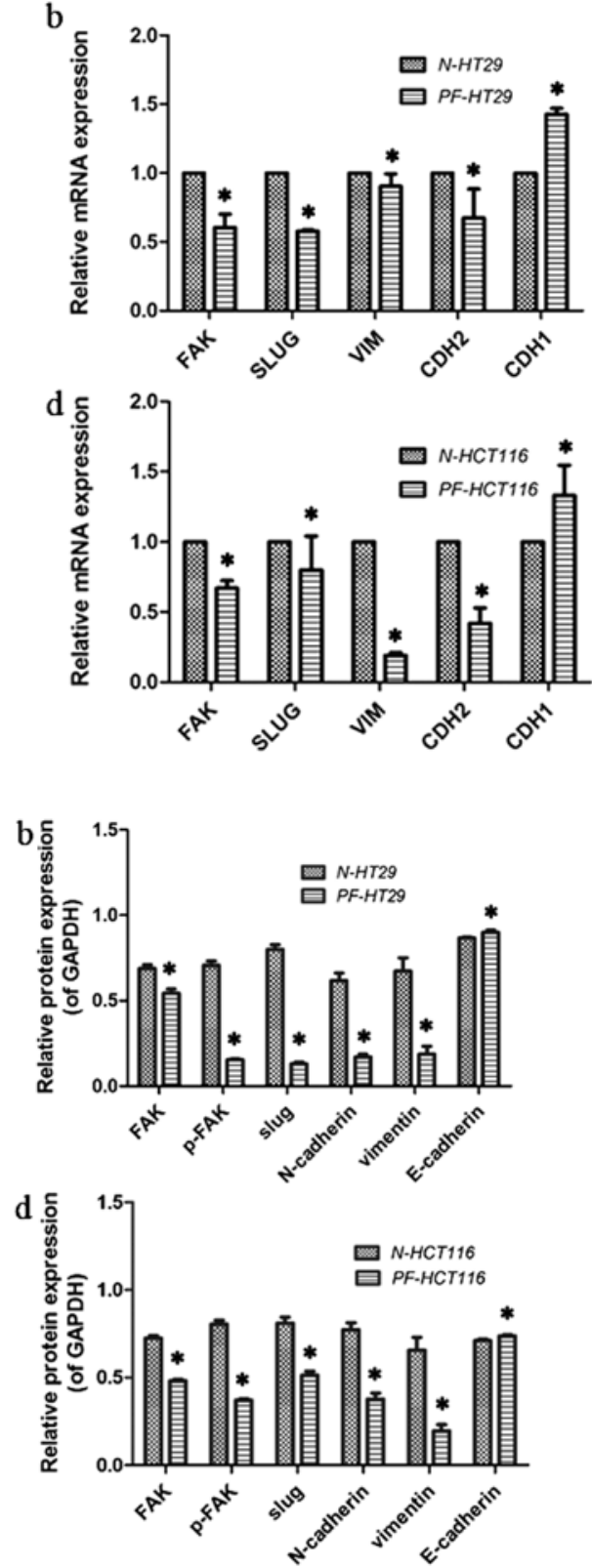

Figure 6. Effects of FAK inhibition of the expression of epithelial-mesenchymal transition (EMT)-related markers. PF group indicates the suppression of FAK by PF-562271 at $5 \mu \mathrm{M}$ for $48 \mathrm{~h}$. (A) Cell migratory ability was examined by Transwell chamber assay (the $\mathrm{N}$ group is shown in Fig. 1). The data were analyzed using the t-test. (B) The mRNA expression of FAK and EMT-related markers was detected by fluorescence-based qPCR. GAPDH was used as a reference and the N group was set to 1 . The PCR data were analyzed using the Mann-Whitney U test. (C) Relative protein expression levels of FAK, p-FAK and EMT-related markers. GAPDH was used as an internal control. The data were analyzed using the t-test. (a) Caco2 cell line. (b) HT29 cell line. (c) RKO cell line. (d) HCT116 cell line. All data are shown as the means $\pm \mathrm{SD}\left({ }^{*} \mathrm{P}<0.05, \mathrm{PF}\right.$ group vs. $\mathrm{N}$ group). 
cells (32). In a previous study, SphK1 was shown to be overexpressed in colon cancer tissue compared with normal colonic tissue. In addition, the expression of SphK1 was found to correlate with the Dukes' stage, histological grading, lymphnode metastasis and distant metastasis. These data indicate that SphK1 may contribute to the metastasis and the malignant phenotype of colon cancer (17).

EMT has been confirmed to be an important step in metastasis and in the change to the malignant phenotype. After EMT has occurred in the cell, cell migratory ability increases, along with an increase in the expression of mesenchymal cell surface markers, and a decrease in the expression of epithelial cell surface markers and vice versa (33-35). Slug is one of the important transcription factors of EMT $(26,36)$. E-cadherin is the molecular marker of epithelial cells (27-29). N-cadherin and vimentin are molecular markers of mesenchymal cells. In a word, they are all indispensable biological markers in the process of EMT. However, it is not yet clear whether SphK1 modulates the expression of EMT-related markers, though SphK1 may contribute to metastasis and to the change to the malignant phenotype.

A previous study demonstrated that the silencing of SphK1 decreased the expression of vimentin and enhanced the expression of E-cadherin in non-small cell lung cancer. Regretfully, Slug and N-cadherin expression was not detected (18). In the present study, the expression of Slug, $\mathrm{N}$-cadherin and vimentin was decreased, whereas that of E-cadherin was increased following the inhibition of SphK1. These results indicate that SphK1 plays a role in regulating the EMT process. Moreover, the migratory ability of CRC cells was found to weaken following the inhibition of the expression of SphK1, which is consistent with the findings of other researchers (37). Thus, SphK1 may regulate cell migration and the EMT process in CRC cells.

However, it is also important to determine the potential mechanism behind the modulatory effects of SphK1 on the expression of EMT-related markers. It was previously found that the FAK pathway is involved in the SphK1-mediated acquisition of the malignant phenotype in colon cancer cells (17). FAK is a $125 \mathrm{kDa}$ non-receptor protein tyrosine kinase that has been shown to be important in the tumorigenesis and development of human tumors (38). Studies have suggested that the FAK pathway positively participates in the EMT process, which is accompanied by a decrease in the expression of E-cadherin, and an increase in the expression of Slug, N-cadherin and vimentin $(32,39,40)$. In our study, the expression of E-cadherin increased, while the expression of Slug, N-cadherin and vimentin decreased following the suppression of FAK. This study also confirmed that the inhibition of SphK1 suppressed the expression of p-FAK in the CRC cell lines, Caco2, HT29, RKO and HCT116, suggesting that SphK1 may be involved in the modulation of the FAK pathway in CRC cells. On the other hand, the results revealed that the inhibition of SphK1 and FAK expression using specific inhibitors had similar effects on the cell migratory ability and on the expression of EMT-related markers. This suggests that SphK1 modulates the EMT process and cell migration by regulating the expression of $\mathrm{p}-\mathrm{FAK}$ in CRC cells.

In conclusion, in this study, we demonstrated that SphK1 modulated the expression of EMT-related markers and cell migration by regulating the expression of p-FAK in the CRC cell lines, Caco2, HT29, RKO and HCT116. Our results provide evidence of the functional role of SphK1 in mediating the EMT process in colon cancer. Thus, SphK1 may be a promising therapeutic target in CRC.

\section{Acknowledgements}

This study was supported in part by grants from the National Nature Science Foundation of China (nos. 81260365 and 81460380), and the Nature Science Foundation of Guangxi (no. 2013GXNSFAA019159).

\section{References}

1. American Cancer Society: Cancer Facts \& Figures 2015. Atlanta: American Cancer Society, 2015 (https://www.cancer. $\mathrm{org} / \mathrm{research} /$ cancer-facts-statistics.html).

2. Xie J, Dong H, Chen H, Zhao R, Sinko PJ, Shen W, Wang J, Lu Y, Yang X, Xie F, et al: Exploring cancer metastasis prevention strategy: Interrupting adhesion of cancer cells to vascular endothelia of potential metastatic tissues by antibody-coated nanomaterial. J Nanobiotechnology 13: 9, 2015.

3. Arvelo F, Sojo F and Cotte C: Cancer and the metastatic substrate. Ecancermedicalscience 10: 701, 2016.

4. Xu J, Qin X, Wang J, Zhang S, Zhong Y, Ren L, Wei Y, Zeng S, Wan D and Zheng S; Society of Surgery; Chinese Medical Association; Committee of Colorectal Cancer, Chinese Anticancer Association: Chinese guidelines for the diagnosis and comprehensive treatment of hepatic metastasis of colorectal cancer. J Cancer Res Clin Oncol 137: 1379-1396, 2011.

5. Liu Y, Wang G, Yang Y, Mei Z, Liang Z, Cui A, Wu T, Liu CY and Cui L: Increased TEAD4 expression and nuclear localization in colorectal cancer promote epithelial-mesenchymal transition and metastasis in a YAP-independent manner. Oncogene 35: 2789-2800, 2015

6. Ma H, Gao L, Li S, Qin J, Chen L, Liu X, Xu P, Wang F, Xiao H, Zhou S, et al: CCR7 enhances TGF- $\beta 1$-induced epithelial-mesenchymal transition and is associated with lymph node metastasis and poor overall survival in gastric cancer. Oncotarget 6 : 24348-24360, 2015.

7. Atmaca A, Wirtz RW, Werner D, Steinmetz K, Claas S, Brueckl WM, Jäger E and Al-Batran SE: SNAI2/SLUG and estrogen receptor mRNA expression are inversely correlated and prognostic of patient outcome in metastatic non-small cell lung cancer. BMC Cancer 15: 300, 2015.

8. Yuan H, Kajiyama H, Ito S, Chen D, Shibata K, Hamaguchi M, Kikkawa F and Senga T: HOXB13 and ALX4 induce SLUG expression for the promotion of EMT and cell invasion in ovarian cancer cells. Oncotarget 6: 13359-13370, 2015.

9. Palma-Nicolás JP and López-Colomé AM: Thrombin induces slug-mediated E-cadherin transcriptional repression and the parallel upregulation of $\mathrm{N}$-cadherin by a transcription-independent mechanism in RPE cells. J Cell Physiol 228: 581-589, 2013.

10. Xie Y, Liu S, Lu W, Yang Q, Williams KD, Binhazim AA, Carver BS, Matusik RJ and Chen Z: Slug regulates E-cadherin repression via p19Arf in prostate tumorigenesis. Mol Oncol 8: 1355-1364, 2014

11. Vuoriluoto K, Haugen H, Kiviluoto S, Mpindi JP, Nevo J, Gjerdrum C, Tiron C, Lorens JB and Ivaska J: Vimentin regulates EMT induction by Slug and oncogenic H-Ras and migration by governing Axl expression in breast cancer. Oncogene 30: 1436-1448, 2011.

12. Xia J, Wu Z, Yu C, He W, Zheng H, He Y, Jian W, Chen L, Zhang L and Li W: miR-124 inhibits cell proliferation in gastric cancer through downregulation of SPHK1. J Pathol 227: 470-480, 2012.

13. Pan J, Tao YF, Zhou Z, Cao BR, Wu SY, Zhang YL, Hu SY, Zhao WL, Wang J, Lou GL, et al: An novel role of sphingosine kinase-1 (SPHK1) in the invasion and metastasis of esophageal carcinoma. J Transl Med 9: 157, 2011.

14. Zhang Z, Yan Z, Yuan Z, Sun Y, He H and Mai C: SPHK1 inhibitor suppresses cell proliferation and invasion associated with the inhibition of NF- $\mathrm{B}$ pathway in hepatocellular carcinoma. Tumour Biol 36: 1503-1509, 2015. 
15. Chen K, Pan Q, Gao Y, Yang X, Wang S, Peppelenbosch MP and Kong X: DMS triggers apoptosis associated with the inhibition of SPHK1/NF- $\kappa \mathrm{B}$ activation and increase in intracellular $\mathrm{Ca}^{2+}$ concentration in human cancer cells. Int J Mol Med 33: 17-24, 2014.

16. Xiong $\mathrm{H}$, Wang J, Guan $\mathrm{H}$, Wu J, Xu R, Wang M, Rong X, Huang K, Huang J, Liao Q, et al: SphK1 confers resistance to apoptosis in gastric cancer cells by downregulating Bim via stimulating Akt/FoxO3a signaling. Oncol Rep 32: 1369-1373, 2014.

17. Liu SQ, Su YJ, Qin MB, Mao YB, Huang JA and Tang GD: Sphingosine kinase 1 promotes tumor progression and confers malignancy phenotypes of colon cancer by regulating the focal adhesion kinase pathway and adhesion molecules. Int J Oncol 42 : 617-626, 2013.

18. Ni M, Shi XL, Qu ZG, Jiang H, Chen ZQ and Hu J: Epithelial mesenchymal transition of non-small-cell lung cancer cells A549 induced by SPHK1. Asian Pac J Trop Med 8: 142-146, 2015.

19. Golubovskaya VM: Targeting FAK in human cancer: From finding to first clinical trials. Front Biosci (Landmark Ed) 19 687-706, 2014.

20. Wilson C, Nicholes K, Bustos D, Lin E, Song Q, Stephan JP, Kirkpatrick DS and Settleman J: Overcoming EMT-associated resistance to anti-cancer drugs via Src/FAK pathway inhibition. Oncotarget 5: 7328-7341, 2014

21. Kuo TC, Tan CT, Chang YW, Hong CC, Lee WJ, Chen MW, Jeng YM, Chiou J, Yu P, Chen PS, et al: Angiopoietin-like protein 1 suppresses SLUG to inhibit cancer cell motility. J Clin Invest 123: 1082-1095, 2013.

22. Gassowska M, Cieslik M, Wilkaniec A and Strosznajder JB: Sphingosine kinases/sphingosine-1-phosphate and death Signalling in APP-transfected cells. Neurochem Res 39: 645-652, 2014.

23. Crompton BD, Carlton AL, Thorner AR, Christie AL, Du J, Calicchio ML, Rivera MN, Fleming MD, Kohl NE, Kung AL, et al: High-throughput tyrosine kinase activity profiling identifies FAK as a candidate therapeutic target in Ewing sarcoma. Cancer Res 73: 2873-2883, 2013.

24. Li X, Gao D, Wang H, Li X, Yang J, Yan X, Liu Z and Ma Z: Negative feedback loop between p66Shc and ZEB1 regulates fibrotic EMT response in lung cancer cells. Cell Death Dis 6 : e1708, 2015.

25. Tiwari N, Gheldof A, Tatari M and Christofori G: EMT as the ultimate survival mechanism of cancer cells. Semin Cancer Biol 22: 194-207, 2012

26. Li Y, Zhao Z, Xu C, Zhou Z, Zhu Z and You T: HMGA2 induces transcription factor Slug expression to promote epithelialto-mesenchymal transition and contributes to colon cancer progression. Cancer Lett 355: 130-140, 2014.

27. Rogers CD, Saxena A and Bronner ME: Sip1 mediates an E-cadherin-to-N-cadherin switch during cranial neural crest EMT. J Cell Biol 203: 835-847, 2013.

28. Zhang X, Liu G, Kang Y, Dong Z, Qian Q and Ma X: N-cadherin expression is associated with acquisition of EMT phenotype and with enhanced invasion in erlotinib-resistant lung cancer cell lines. PLoS One 8: e57692, 2013.
29. da Silva SD, Morand GB, Alobaid FA, Hier MP, Mlynarek AM, Alaoui-Jamali MA and Kowalski LP: Epithelial-mesenchymal transition (EMT) markers have prognostic impact in multiple primary oral squamous cell carcinoma. Clin Exp Metastasis 32: 55-63, 2015.

30. Taliaferro-Smith L, Oberlick E, Liu T, McGlothen T, Alcaide T, Tobin R, Donnelly S, Commander R, Kline E, Nagaraju GP, et al: FAK activation is required for IGF1R-mediated regulation of EMT, migration, and invasion in mesenchymal triple negative breast cancer cells. Oncotarget 6: 4757-4772, 2015.

31. John JK, Paraiso KH, Rebecca VW, Cantini LP, Abel EV, Pagano N, Meggers E, Mathew R, Krepler C, Izumi V, et al: GSK3 $\beta$ inhibition blocks melanoma cell/host interactions by downregulating $\mathrm{N}$-cadherin expression and decreasing FAK phosphorylation. J Invest Dermatol 132: 2818-2827, 2012.

32. Datta A, Loo SY, Huang B, Wong L, Tan SS, Tan TZ, Lee SC, Thiery JP, Lim YC, Yong WP, et al: SPHK1 regulates proliferation and survival responses in triple-negative breast cancer. Oncotarget 5: 5920-5933, 2014.

33. Huo C, Kao YH and Chuu CP: Androgen receptor inhibits epithelial-mesenchymal transition, migration, and invasion of PC-3 prostate cancer cells. Cancer Lett 369: 103-111, 2015.

34. Cheng G, Liu C, Sun X, Zhang L, Liu L, Ouyang J and Li B Visfatin promotes osteosarcoma cell migration and invasion via induction of epithelial-mesenchymal transition. Oncol Rep 34: 987-994, 2015.

35. Räsänen K and Vaheri A: TGF-beta1 causes epithelial-mesenchymal transition in $\mathrm{HaCaT}$ derivatives, but induces expression of COX-2 and migration only in benign, not in malignant keratinocytes. J Dermatol Sci 58: 97-104, 2010.

36. Lamouille S, Xu J and Derynck R: Molecular mechanisms of epithelial-mesenchymal transition. Nat Rev Mol Cell Biol 15: 178-196, 2014.

37. Chen MB, Yang L, Lu PH, Fu XL, Zhang Y, Zhu YQ and Tian Y: MicroRNA-101 downregulates sphingosine kinase 1 in colorectal cancer cells. Biochem Biophys Res Commun 463: 954-960, 2015.

38. Stewart JE, Ma X, Megison M, Nabers H, Cance WG, Kurenova EV and Beierle EA: Inhibition of FAK and VEGFR-3 binding decreases tumorigenicity in neuroblastoma. Mol Carcinog 54: 9-23, 2015.

39. Hsieh YS, Chu SC, Hsu LS, Chen KS, Lai MT, Yeh CH and Chen PN: Rubus idaeus L. reverses epithelial-to-mesenchymal transition and suppresses cell invasion and protease activities by targeting ERK1/2 and FAK pathways in human lung cancer cells. Food Chem Toxicol 62: 908-918, 2013

40. Chen KS, Shi MD, Chien CS and Shih YW: Pinocembrin suppresses TGF- $\beta 1$-induced epithelial-mesenchymal transition and metastasis of human Y-79 retinoblastoma cells through inactivating $\alpha v \beta 3$ integrin/FAK/p38 $\alpha$ signaling pathway. Cell Biosci 4: 41, 2014. 